\title{
Aripiprazole Attenuates the Discriminative-Stimulus and Subject-Rated Effects of D-Amphetamine in Humans
}

\author{
Joshua A Lile', William W Stoops' ${ }^{1,2}$, Andrea R Vansickel', ${ }^{1,2}$ Paul EA Glaser ${ }^{3,4,5}$, Lon R Hays $s^{1,3,6}$ \\ and Craig R Rush*, ${ }^{*, 2,3}$ \\ 'Department of Behavioral Science, College of Medicine, University of Kentucky, Lexington, KY, USA; ${ }^{2}$ Department of Psychology, College of Arts \\ and Sciences, University of Kentucky, Lexington, KY, USA; ${ }^{3}$ Department of Psychiatry, College of Medicine, University of Kentucky, Lexington, KY, \\ USA; ${ }^{4}$ Department of Anatomy and Neurobiology, College of Medicine, University of Kentucky, Lexington, KY, USA; ${ }^{5}$ Department of Pediatrics, \\ College of Medicine, University of Kentucky, Lexington, KY, USA; ${ }^{6}$ Department of Internal Medicine, College of Medicine, University of Kentucky, \\ Lexington, KY, USA
}

\begin{abstract}
The results of animal research suggest that the use of partial agonists at dopamine (DA) $D_{2}$ receptors may be an effective strategy for the treatment of stimulant dependence. Aripiprazole is an atypical antipsychotic that has partial agonist activity at $\mathrm{D}_{2}$ receptors. In this experiment, seven human participants with a history of nontherapeutic stimulant use learned to discriminate $15 \mathrm{mg}$ oral D-amphetamine. After acquiring the discrimination (ie $\geqslant 80 \%$ correct responding on four consecutive sessions), the effects of a range of doses of $D-$ amphetamine $(0,2.5,5,10$, and $15 \mathrm{mg})$, alone and in combination with aripiprazole $(0$ and $20 \mathrm{mg})$, were assessed. D-Amphetamine alone functioned as a discriminative stimulus, produced prototypical subject-rated drug effects (eg increased ratings of Active, Alert, Energetic) and elevated cardiovascular indices. These effects were generally a function of dose. Aripiprazole alone did not occasion D-amphetamineappropriate responding or produce subject-rated effects, but modestly impaired performance. Administration of aripiprazole significantly attenuated the discriminative-stimulus and cardiovascular effects of D-amphetamine, as well as some of the subject-rated drug effects. These data are consistent with previous preclinical findings and suggest that DA partial agonists deserve further evaluation as potential pharmacotherapies in the management of stimulant dependence. Future studies should investigate the ability of aripiprazole or related compounds to attenuate the behavioral effects of stimulants associated with a greater degree of dependence, such as methamphetamine or cocaine, in dependent individuals.

Neuropsychopharmacology (2005) 30, 2 I03-2 I 14. doi:I0.1038/s..npp. I 300803; published online 29 June 2005
\end{abstract}

Keywords: D-amphetamine; aripiprazole; drug discrimination; partial agonist; psychomotor performance; subjective effects

\section{INTRODUCTION}

The abuse of psychomotor stimulants remains a significant public health concern. In particular, amphetamine abuse and dependence is escalating at an alarming rate. Methamphetamine is the primary form of amphetamine used recreationally in the United States (Substance Abuse and Mental Health Services Administration (SAMHSA), 2004). Between 1996 and 2002, the number of Americans who reported methamphetamine use increased by $250 \%(4.8$ million in 1996, 12 million in 2002; SAMHSA, 2003).

$\overline{\text { A National Institute on Drug Abuse Grant DA } 10325 \text { (CRR) supported }}$ this research.

*Correspondence: Dr CR Rush, Department of Behavioral Science, University of Kentucky, Lexington, KY 40536-0086, USA, Tel: + I 859 323 6I30, Fax: + I 859323 5350, E-mail: crush2@uky.edu

Received 24 February 2005; revised 22 April 2005; accepted 16 May 2005

Online publication: 24 May 2005 at http://www.acnp.org/citations/ Npp052405050 126/default.pdf
Consistent with those findings, data from the Arrestee Drug Abuse Monitoring Program (ADAM) indicated that methamphetamine use has grown considerably from 1991 to 2001, especially in the Western and Midwestern parts of the country (Yacoubian and Peters, 2004). Between 1992 and 2002, per capita rates of admissions to treatment programs for amphetamine increased by over $500 \%$, and methamphetamine made up $90 \%$ of these admissions (SAMHSA, 2004). The escalating rates of methamphetamine use are consistent with greater drug availability. From 1991 to 2001, increasingly larger amounts of methamphetamine and its precursors have been seized worldwide, and the number of clandestine manufacturing laboratories that have been discovered has risen (United Nations Office on Drugs and Crime, 2003).

One strategy that may be particularly effective at treating stimulant dependence is the use of partial agonists at the receptor systems implicated in mediating their effects (Childress and O'Brien, 2000). Partial agonists are receptor ligands with significant receptor affinity, but low intrinsic 
activity. Theoretically, these drugs may be expected to have the therapeutic advantages of both agonists and antagonists. Under conditions of low neurotransmitter tone, as is observed for dopamine (DA) during initial abstinence from chronic stimulant administration (Weiss et al, 1992), a partial agonist should produce some receptor stimulation, and may therefore function as a replacement medication. In contrast, a partial agonist may act as an antagonist when there are higher levels of neurotransmitter present in the synapse, as would occur following use of a stimulant upon relapse. In the management of opioid dependence, the partial $\mu$ agonist buprenorphine appears to be effective in this manner (reviewed in Gonzalez et al, 2004).

Psychomotor stimulants increase synaptic levels of DA, serotonin (5-HT), and norepinephrine. While each of these monoamine neurotransmitter systems is involved in the behavioral effects of stimulants, there is an extensive literature emphasizing the role of DA. In particular, the $\mathrm{D}_{2}$ receptor subtype appears especially important (Volkow et al, 1999). Results from animal studies suggest that $\mathrm{D}_{2}$ receptor partial agonists may be useful as pharmacological adjuncts for the treatment of stimulant addiction. For example, in a laboratory model of drug withdrawal, rats that were trained to self-administer sucrose on a progressiveratio schedule received repeated, increasing doses of $\mathrm{D}$ amphetamine, and were then given either placebo or the $D_{2}$ partial agonist terguride. Break points for sucrose were reduced when $\mathrm{D}$-amphetamine injections were withheld, but returned to baseline when terguride was administered (Orsini et al, 2001). In drug self-administration studies, pretreatment with $\mathrm{D}_{2}$ partial agonists attenuated the reinforcing effects of stimulants (Izzo et al, 2001; Pulvirenti et al, 1998). Similarly, in rats trained to discriminate injections of D-amphetamine, the partial agonists, preclamol, SDZ 208-911, and SDZ 208-912 attenuated its discriminative stimulus effects (Exner and Clark, 1992). There do not appear to be any clinical or laboratory studies that have examined the efficacy of a partial $D_{2}$ agonist for stimulant dependence in humans.

Aripiprazole $\left(\right.$ Abilify $^{\mathbb{R}}$ ) is an atypical antipsychotic that is a partial agonist at $D_{2}$ receptors (Burris et al, 2002). The purpose of the present study was to evaluate the ability of aripiprazole to attenuate the effects of $\mathrm{D}$-amphetamine that are associated with the abuse of stimulants. This initial study was conducted to obtain preliminary data regarding the impact of aripiprazole on the effects of D-amphetamine before undertaking a more indepth evaluation testing multiple doses of aripiprazole and a stimulant associated with a greater degree of dependence such as methamphetamine in dependent individuals. In this study, the discriminative-stimulus effects of D-amphetamine $(0,2.5$, 5,10 , and $15 \mathrm{mg}$ ), alone and in combination with aripiprazole ( 0 and $20 \mathrm{mg}$ ), were assessed in healthy humans with a history of nontherapeutic use of a stimulant. Drug-discrimination procedures have been used extensively with animals to characterize the interoceptive-stimulus effects of stimulants like D-amphetamine, but much less so with humans. Conducting drug-discrimination experiments with humans is important to determine to what extent findings with laboratory animals generalize to humans. Moreover, because drug-discrimination procedures involve extensive training before novel doses and drug combinations are tested, between-subject variability should be decreased. To more fully characterize the effects of these drugs and drug combinations, a battery of self-reported drug-effect questionnaires, a performance task and physiological indices were also included. We hypothesized that, when administered concurrently, $20 \mathrm{mg}$ aripiprazole would act as an antagonist and result in rightward shifts in the D-amphetamine dose-effect curve.

\section{METHODS}

\section{Participants}

Nine healthy adults were recruited via newspaper ads, flyers and word-of-mouth to participate in this experiment. Participants were paid $\$ 40 /$ session to participate in this experiment and received performance-based payment as outlined below. One participant was unable to accurately discriminate $15 \mathrm{mg}$ D-amphetamine, while another participant withdrew for reasons unrelated to the study protocol. Data from these participants were not included in the analyses. Seven participants (two males, five females) completed this experiment. These participants ranged in age from 20 to 30 years (mean $=22$ ), in education from 13 to 16 years $($ mean $=14$ ) and in weight from 52.3 to $96.8 \mathrm{~kg}$ (mean $=67.3$ ). All participants were required to have a lifetime history of nontherapeutic use of a stimulant (eg cocaine, D-amphetamine, ecstasy, ephedrine). Participants also reported prior histories of other illicit drug use, including marijuana, benzodiazepines, hallucinogens, and opiates. With the exception of one volunteer who regularly used marijuana, none reported current use of these drugs. These participants reported consuming 0-188 mg caffeine/ day $($ mean $=71.4)$. Five participants were current smokers of tobacco cigarettes (mean $=10$ cigarettes/day). Participants completed questionnaires assessing drug use, physical, and psychiatric histories. Individuals with current or past histories of Axis I psychiatric disorder, including substance abuse/dependence disorders (except nicotine), were excluded from participating. All participants were in good health, with no contraindications to stimulant or antipsychotic medications. Drug urine screens conducted during the initial screening were negative for amphetamine, barbiturates, cocaine, and opioids (OnTrak TESTSTIK, Varian, Inc., Lake Forest, CA). One participant tested positive for tetrahydrocannibinol (THC) and another participant tested positive for benzodiazepines. Four of the five female participants used a hormonal contraceptive. The other female participant agreed to abstain from sexual activity for the duration of the study. In the female participants, urine pregnancy tests taken before and during study participation were negative. This study was conducted in accordance with the Helsinki Declaration of 1975. The Institutional Review Board of the University of Kentucky Medical Center approved the study and the informed consent document. All participants gave their written informed consent and the confidentiality of their personal information was maintained throughout. 


\section{General Procedures}

Participants enrolled as outpatients at the Laboratory of Human Behavioral Pharmacology at the University of Kentucky Medical Center Monday through Friday for 24$34($ mean $=29)$ experimental sessions. Participants were informed that during their participation they would receive various drugs and that these could include placebo and medications indicated for the treatment of attention-deficit and hyperactivity disorder and psychotic disorders. Participants were told that the purpose of the study was to see if they could detect the presence of a drug, and how drugs affect mood and behavior. Other than receiving this general information, participants were blind to the type of drug administered, and were given no instructions regarding what they were 'supposed' to do or what outcomes might be expected.

Prior to initiating drug testing, participants completed two 'practice' sessions. These 'practice' sessions were used to familiarize participants with the drug-discrimination task, self-reported drug-effect questionnaires, performance measure, and daily laboratory routine. No drugs were administered on these sessions.

Throughout the study, participants were required to abstain from using all illicit psychoactive drugs, caffeine and solid food for $4 \mathrm{~h}$ prior to a scheduled experimental session, and alcohol for $12 \mathrm{~h}$ prior to, and following, a scheduled experimental session. On each experimentalsession day, participants arrived at the laboratory and provided a urine sample before drug administration, which was screened for the presence of amphetamine, barbiturates, benzodiazepines, cocaine, opioids, and THC. These urine samples were occasionally positive for amphetamine, which coincided with experimental administration. One participant's urine specimen was positive for THC on the first practice session, while another participant's urine specimen was positive for THC 14 times, the majority of which occurred consecutively during the initial sessions of the experimental protocol. Participants also provided an expired air specimen, which was assayed for the presence of alcohol using a hand-held breathalyzer (Intoximeters, Inc., St Louis, MO). Two participants were sent home, each on one occasion, for having a positive breath-alcohol level. Otherwise, all expired air samples were negative.

On experimental-session days, participants completed the self-reported drug-effect questionnaires and performance task approximately $30 \mathrm{~min}$ before drug administration, and then completed the drug-discrimination task, self-reported drug-effect questionnaires, and performance task 1, 2, 3, 4, and $5 \mathrm{~h}$ after drug administration. When not completing the drug-discrimination task, self-reported questionnaires, and performance task, participants were allowed to engage in recreational activities (eg watch television, play cards, read, or socialize). Participants were provided with a fat-free breakfast when they arrived at the laboratory and lunch after the 3-h observation.

\section{Drug-Discrimination Procedures}

This experiment consisted of three phases, which were completed in fixed order: (1) sampling phase, (2) acquisition phase, and (3) test phase.
Sampling phase. All participants completed two sampling sessions to acquaint them with the drug effects. During each sampling session, participants ingested four capsules that contained a total of $15 \mathrm{mg}$ D-amphetamine. D-Amphetamine was identified by letter code (eg DRUG A), but the participants were not explicitly informed of the capsules' contents. D-Amphetamine (15 mg) is identified as DRUG A for illustrative purposes only; a unique letter code was used for each participant. An instruction set was given to each participant during the sampling phase. Participants were asked to carefully read the instructions before each sampling session, and a research assistant also read the instructions aloud. Briefly, the instructions explained that they were receiving DRUG A, but in the future they would be asked to decide whether they had received DRUG A or NOT DRUG A (for the exact instructions, see Rush et al, 2003).

Acquisition phase. Following the sampling phase, an acquisition phase was conducted to determine if participants could discriminate $15 \mathrm{mg}$ D-amphetamine. During this phase, participants ingested capsules under double-blind conditions, and were not told whether the capsules contained $15 \mathrm{mg}$ D-amphetamine (eg DRUG A) or placebo (eg NOT DRUG A). Participants were not explicitly instructed that they would be attempting to acquire a drug vs. placebo discrimination (for the exact instructions, see Rush et al, 2003). After capsule administration, participants completed the drug-discrimination task, self-reported drugeffect questionnaires, and performance measure periodically for $5 \mathrm{~h}$. Participants were instructed that they could change their responses on the drug-discrimination task between hours $1,2,3,4$, and 5, based on what they believed at the time. After completing the drug-discrimination task, self-reported drug-effect questionnaires, and performance task at the 5-h observation, participants opened a sealed envelope that informed the participant and the research assistant of the identity of the drug administered (ie DRUG A or NOT DRUG A). The criterion for having acquired the discrimination was $\geqslant 80 \%$ correct responding on four consecutive sessions on the drug-discrimination task described below. The order of drug administration was random, except that each participant received each training condition, $15 \mathrm{mg}$ D-amphetamine, and placebo, at least twice.

Test phase. Following the acquisition phase, participants entered a test phase. The test phase consisted of test sessions interspersed with acquisition sessions. Approximately $46 \%$ of these sessions were test sessions, and the remainder were acquisition sessions. As noted above, participants were instructed that there would be sessions for which they would not be given any feedback concerning the accuracy of their drug-discrimination performance, and that on these sessions they would be credited with the greater number of points allocated to the DRUG A or NOT DRUG A option. Thus, these sessions were similar to the acquisition sessions, except that participants did not receive any feedback concerning their drug-discrimination performance and they earned the bonus money allocated to DRUG A or NOT DRUG A, whichever was greater. Participants 
were not told the purpose of these 'test' sessions, nor did they know when they were scheduled until after they opened the sealed envelope.

To ensure that participants continued to reliably discriminate $15 \mathrm{mg}$ D-amphetamine throughout the test phase, acquisition sessions were intermixed among the test sessions. These acquisition sessions were identical to those in the acquisition phase (ie participants received $15 \mathrm{mg}$ Damphetamine or placebo), completed the drug-discrimination task periodically for $5 \mathrm{~h}$ after drug administration, were informed whether they had received DRUG A or NOT DRUG $A$, and received bonus money contingent upon the accuracy of their drug-discrimination performance. If a participant responded incorrectly on an acquisition day (ie $<80 \%$ correct), additional acquisition sessions were scheduled. These additional acquisition sessions continued until the participant correctly identified at least one of the conditions (ie $15 \mathrm{mg}$ D-amphetamine or placebo).

In all, $10 \mathrm{D}$-amphetamine-aripiprazole conditions were studied during the test phase: (1) $0 \mathrm{mg}$ D-amphetamine plus $0 \mathrm{mg}$ aripiprazole; (2) $2.5 \mathrm{mg}$ D-amphetamine plus $0 \mathrm{mg}$ aripiprazole; (3) $5 \mathrm{mg}$ D-amphetamine plus $0 \mathrm{mg}$ aripiprazole; (4) $10 \mathrm{mg}$ D-amphetamine plus $0 \mathrm{mg}$ aripiprazole; 5) $15 \mathrm{mg}$ D-amphetamine plus $0 \mathrm{mg}$ aripiprazole; (6) $0 \mathrm{mg}$ D-amphetamine plus $20 \mathrm{mg}$ aripiprazole; (7) $2.5 \mathrm{D}$-amphetamine plus $20 \mathrm{mg}$ aripiprazole; 8) $5 \mathrm{mg}$ D-amphetamine plus $20 \mathrm{mg}$ aripiprazole; (9) $10 \mathrm{mg}$ D-amphetamine plus $20 \mathrm{mg}$ aripiprazole; and (10) $15 \mathrm{mg}$ D-amphetamine plus $20 \mathrm{mg}$ aripiprazole. The order of drug administration during this phase of the experiment was random, with three exceptions. First, an active drug dose was never administered on more than three consecutive sessions. Second, aripiprazole was administered alone before D-amphetamine-aripiprazole combinations were tested. Third, because aripiprazole has a long half-life (approximately $60 \mathrm{~h}$; McGavin and Goa, 2002), the experimental session that followed aripiprazole administration was scheduled at least $48 \mathrm{~h}$ later and consisted of the active acquisition condition (ie $15 \mathrm{mg}$ D-amphetamine) to ensure that there were no residual effects.

\section{Drug-Discrimination Measure}

A point-distribution drug-discrimination task (Rush et al, 2003,2004 ) was completed $1,2,3,4$, and $5 \mathrm{~h}$ after oral drug administration on an Apple Macintosh computer (Apple Computer, Inc., Cupertino, CA). In this procedure, the participant distributed 100 points between two options (ie DRUG A or NOT DRUG A). During acquisition sessions, points accumulated on the correct option were exchangeable for money at a rate of $\$ 0.08 /$ point. During test sessions, participants were credited with the greater number of points allocated to the DRUG A or NOT DRUG A option, which were exchangeable at the same rate. Thus, participants were able to earn a maximum of $\$ 40.00$ /session on this task. The dependent measure in this procedure was percent D-amphetamine-appropriate responding.

\section{Self-Report Questionnaires, Performance Task, Cardiovascular Measures}

Self-reported drug-effect questionnaires were administered on an Apple Macintosh computer and were completed in fixed order. These questionnaires were completed approximately 30 min before drug administration, and 1, 2, 3, 4, and $5 \mathrm{~h}$ after drug administration.

Addiction Research Center Inventory (ARCI). The short form of the ARCI consisted of 49 true/false questions and contained five major subscales: the morphine-benzedrine group (MBG; a measure of euphoria), the pentobarbital, chlorpromazine, alcohol group (PCAG; a measure of sedation), the lysergic acid diethylamide (LSD; a measure of dysphoria), and the benzedrine group and amphetamine scales (BG and A, respectively; Stimulant-Sensitive Scales) (Jasinski, 1977; Martin et al, 1971).

Adjective-Rating Scale. The Adjective-Rating Scale consisted of 32 items and contained two subscales: Sedative and Stimulant. These subscales are sensitive to the acute effects of orally administered sedative and stimulant drugs (Oliveto et al, 1992). Participants rated each item using the computer mouse to point to and select among one of five response options: Not at All, A Little Bit, Moderately, Quite a Bit, and Extremely (scored numerically from 0 to 4 , respectively).

Drug-Effect Questionnaire. The Drug-Effect Questionnaire consisted of 20 items. This questionnaire is sensitive to the acute effects of orally administered stimulants (Rush et al, 2003, 2004). In all, 20 items were presented on the video screen, one at a time. Participants rated each adjective with a five-point scale similar to the one described above. For the individual items, see Rush et al (2003).

Stimulant-Sensitive Adjective-Rating Scale. The Stimulant-Sensitive Adjective-Rating Scale consisted of 21 items. This scale is sensitive to the acute effects of orally administered stimulants (Di Marino et al, 1998). Participants rated each item using a five-point scale identical to the one described above. Responses to individual items are summed to create a composite score.

Digit-Symbol-Substitution Test (DSST). A computerized version of the DSST, which has been described previously, was used in this experiment (McLeod et al, 1982). This measure is sensitive to the effects of orally administered sedative and stimulant drugs (Rush et al, 2003). Briefly, participants used a numeric keypad to enter a geometric pattern associated with one of nine digits displayed on a video screen. Participants had $90 \mathrm{~s}$ to enter as many geometric patterns as possible. The dependent measure was the number of patterns the participant entered correctly (ie trials correct) and the number of patterns the participant completed (ie trials completed).

Heart rate and blood pressure. Heart rate and blood pressure were recorded using an automated blood-pressure monitor (DINAMAP, Johnson and Johnson, Alexandria, TX). Heart rate and blood pressure were monitored for approximately $30 \mathrm{~min}$ before drug administration and at hourly intervals for $5 \mathrm{~h}$ afterwards. Heart rate and blood pressure were recorded immediately before participants completed the drug-discrimination, self-reported drugeffect questionnaires, and performance task. 


\section{Drug Administration}

D-Amphetamine doses were prepared by overencapsulating 2.5 or $5 \mathrm{mg}$ of commercially generic formulation (Barr Laboratories, Inc., Pomona, NY) in a size 0 capsule. Aripiprazole doses were prepared by overencapsulating $20 \mathrm{mg}$ of commercially available drug (Abilify ${ }^{\circledR}$, Janssen Pharmaceutica, Titusville, NJ) in identical capsules. Cornstarch was used to fill the remainder of all the capsules. Placebo capsules contained only cornstarch.

During each experimental session, participants ingested four capsules (ie three D-amphetamine- or placebo-containing capsules, and one aripiprazole or placebo-containing capsule). Administering the appropriate number of drug- or placebo-containing capsules varied the dose. Capsules were taken orally with approximately $150 \mathrm{ml}$ of water. Drugadministration procedures were designed to ensure that participants swallowed the capsules. To accomplish this, the research assistant: (a) watched the participant to ensure that he/she swallowed the capsules and did not remove them from his/her mouth, (b) conducted a brief oral examination to ensure that the participant was not hiding the capsules under his/her tongue, and (c) spoke with the participant to determine if they had anything in their mouth.

D-Amphetamine doses were chosen based on the results from previous human behavioral pharmacology research (Kollins and Rush, 1999; Rush et al, 1998, 2003, 2004). The active aripiprazole dose was chosen based on the recommended acute dosing range for the treatment of psychotic disorders, which is $15-30 \mathrm{mg}$, s.i.d. (McGavin and Goa, 2002). The behavioral effects of D-amphetamine peak approximately $2-3 \mathrm{~h}$ after oral administration (Chait et al, 1985; Rush et al, 1998). Peak aripiprazole plasma concentrations occur approximately $3-4 \mathrm{~h}$ after oral administration (McGavin and Goa, 2002). Based on these pharmacokinetic data, D-amphetamine and aripiprazole were administered simultaneously to assess behavioral effects across peak plasma levels of both drugs.

References below to placebo pertain to sessions in which placebo doses of both D-amphetamine and aripiprazole were administered. References to D-amphetamine alone pertain to sessions in which an active dose of $\mathrm{D}$ amphetamine was administered in combination with $0 \mathrm{mg}$ aripiprazole. References to aripiprazole alone pertain to sessions in which the active dose of aripiprazole was administered in combination with $0 \mathrm{mg} \mathrm{D}$-amphetamine.

\section{Data Analysis}

Statistical analyses of group data were conducted to examine drug effects on the drug-discrimination task, selfreported drug-effect questionnaires and performance measure. Effects were considered significant for $p \leqslant 0.05$. For the $15 \mathrm{mg}$ D-amphetamine alone and placebo conditions, data were averaged across the four sessions of the acquisition phase in which the participant met the discrimination criterion as well as all exposures to these conditions in the test phase. Drug-discrimination data were analyzed statistically as the total percent of points allocated to the drug option across the 5-h session (ie percent drug-appropriate responding). Self-reported drug-effect questionnaire and performance data were analyzed statistically as area-under- the-time-action curve (AUC), which was calculated using the trapezoidal method, and as peak effect. Data were analyzed by two-factor repeated-measure analysis of variance (ANOVA) with D-amphetamine $(0,2.5,5,10$, and $15 \mathrm{mg}$ ) and aripiprazole (0 and $20 \mathrm{mg}$ ) as factors (StatView 5.0.1, SAS Institute Inc., Cary, NC). Results from the AUC and peak effect analyses were nearly identical; so, for brevity, only AUC data are presented here. Planned comparisons (ie Fisher's least significant difference) were conducted if a significant effect of $\mathrm{D}$-amphetamine or aripiprazole, or an interaction of these two factors, was detected. These planned comparisons were used to make appropriate pairwise comparisons between means. Planned comparisons were first conducted to compare each of the nine active drug conditions with placebo. Next, if a dose of D-amphetamine alone increased responding significantly above placebo, planned comparisons were conducted to compare the effects of these doses of $\mathrm{D}$-amphetamine alone and in combination with $20 \mathrm{mg}$ aripiprazole. Finally, if aripiprazole alone significantly altered responding compared to placebo, planned comparisons were conducted to compare this condition with each of the D-amphetaminearipiprazole conditions.

\section{RESULTS}

\section{Drug Discrimination Performance}

The seven participants met the discrimination criterion in an average of 5.1 sessions (range $=4-11$ ). ANOVA revealed a significant interaction of aripiprazole and D-amphetamine (Table 1). D-Amphetamine (2.5, 5, 10, and $15 \mathrm{mg}$ ) alone increased drug-appropriate responding above placebo levels, whereas only the $15 \mathrm{mg}$ dose did so when Damphetamine was administered in combination with $20 \mathrm{mg}$ aripiprazole (Figure 1). The percentage of drugappropriate responding was significantly lower after the administration of all active D-amphetamine doses in combination with $20 \mathrm{mg}$ aripiprazole, relative to those D-amphetamine doses alone.

\section{ARCI}

ANOVA revealed a significant main effect of D-amphetamine on the A, BG, MBG, and PCAG scales, and a main effect of aripiprazole on the A and LSD scales of the ARCI (Table 1). Figure 2 shows the effects of D-amphetamine alone, and in combination with aripiprazole, for the A, MBG, and PCAG scales. For brevity, only the data presented in these figures will be described here in detail. The 5, 10, and $15 \mathrm{mg}$ doses of $\mathrm{D}$-amphetamine alone increased scores on the A scale significantly above placebo levels, whereas only the $15 \mathrm{mg}$ dose did so when D-amphetamine was administered in combination with $20 \mathrm{mg}$ aripiprazole. The combination of 5 and $10 \mathrm{mg}$ of D-amphetamine with $20 \mathrm{mg}$ aripiprazole significantly decreased scores on the A scale relative to those doses of $\mathrm{D}$-amphetamine alone. For the MBG scale, the 10 and $15 \mathrm{mg}$ doses of $\mathrm{D}$-amphetamine alone increased scores, but when combined with aripiprazole, there were no doses of D-amphetamine that significantly increased subject ratings. With respect to the PCAG scale, D-amphetamine (10 and $15 \mathrm{mg}$ ) alone decreased scores 
Table I Significant F-values of Experimental Measures for which a Significant Main Effect or Interaction was Obtained

\begin{tabular}{|c|c|c|c|}
\hline Measure & $\begin{array}{l}\text { Aripiprazole } \\
\left(\mathrm{DF}_{1,6}\right)\end{array}$ & $\begin{array}{c}\text { D-Amphetamine } \\
\left(\mathrm{DF}_{4,24}\right)\end{array}$ & $\begin{array}{c}\text { Aripiprazole } \times \\
\text { D-amphetamine } \\
\left(\mathrm{DF}_{\mathbf{4}, 24)}\right.\end{array}$ \\
\hline Drug Discrimination & $50.9 * * * *$ & $7.9 * * * *$ & $3.4 *$ \\
\hline \multicolumn{4}{|l|}{$\mathrm{ARCl}$} \\
\hline A & 10.5 ** & $5.3 * *$ & 1.4 \\
\hline BG & 4.2 & $4.2 * * *$ & 1.0 \\
\hline LSD & $5.8^{*}$ & 2.6 & 2.2 \\
\hline MBG & 5.2 & $4.5 * * 6$ & 2.3 \\
\hline PCAG & 4.2 & $2.9 *$ & 2.3 \\
\hline \multicolumn{4}{|l|}{ Adjective-Rating Scale } \\
\hline Stimulant & $5.6 *$ & 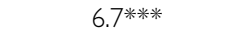 & 1.4 \\
\hline \multicolumn{4}{|c|}{ Stimulant-Sensitive Adjective-Rating Scale } \\
\hline Total & 3.0 & 8.7 米米 & 1.9 \\
\hline \multicolumn{4}{|c|}{ Drug-Effect Questionnaire } \\
\hline $\begin{array}{l}\text { Active/Alert/ } \\
\text { Energetic }\end{array}$ & $6.2^{*}$ & $8.0^{* * * * *}$ & 2.0 \\
\hline Any Effect & 4.9 & 3.0* & 0.7 \\
\hline Good Effect & 4.5 & $6.1 * * *$ & $2.8^{*}$ \\
\hline Heart Racing & I5.7*** & $2.7^{*}$ & 1.4 \\
\hline Like Drug & 4.0 & $5.4 * *$ & $3.7 * * *$ \\
\hline $\begin{array}{l}\text { Performance } \\
\text { Improved }\end{array}$ & 4.8 & $7.0^{* * * * *}$ & 2.2 \\
\hline Willing to Pay For & 4.0 & $3.8 * * *$ & 1.3 \\
\hline Restless & 3.8 & $2.9^{*}$ & 1.2 \\
\hline Shaky/Jittery & $6.7^{*}$ & $3.1^{*}$ & 1.9 \\
\hline Stimulated & 2.8 & $5.6 * *$ & 2.1 \\
\hline $\begin{array}{l}\text { Willing to Take } \\
\text { Again }\end{array}$ & 3.8 & 6.1 $1 * *$ & $3.6 * *$ \\
\hline Talkative/Friendly & 2.3 & $5.3 * *$ & 1.6 \\
\hline DSST & $9.5 *$ & $7.6 * * * * 6$ & 1.3 \\
\hline \multicolumn{4}{|l|}{ Vitals } \\
\hline Systolic pressure & 1.4 & $11.7 * * * *$ & $3.7 * *$ \\
\hline Diastolic pressure & |4.1 1 ***** & $|1$.$| ****$ & $3.3^{*}$ \\
\hline
\end{tabular}

$* p \leqslant 0.05 ; * * * \leqslant 0.01 ; * * * p \leqslant 0.001$.

significantly below placebo levels. In contrast, the combination of 2.5 and $5 \mathrm{mg}$ of $\mathrm{D}$-amphetamine with $20 \mathrm{mg}$ aripiprazole significantly increased scores on the PCAG scale above placebo levels. Scores on this scale following administration of all active doses of $\mathrm{D}$-amphetamine alone were significantly lower relative to those doses in combination with $20 \mathrm{mg}$ aripiprazole.

\section{Adjective-Rating Scale}

ANOVA revealed significant main effects of aripiprazole and D-amphetamine (Table 1) on scores on the Stimulant

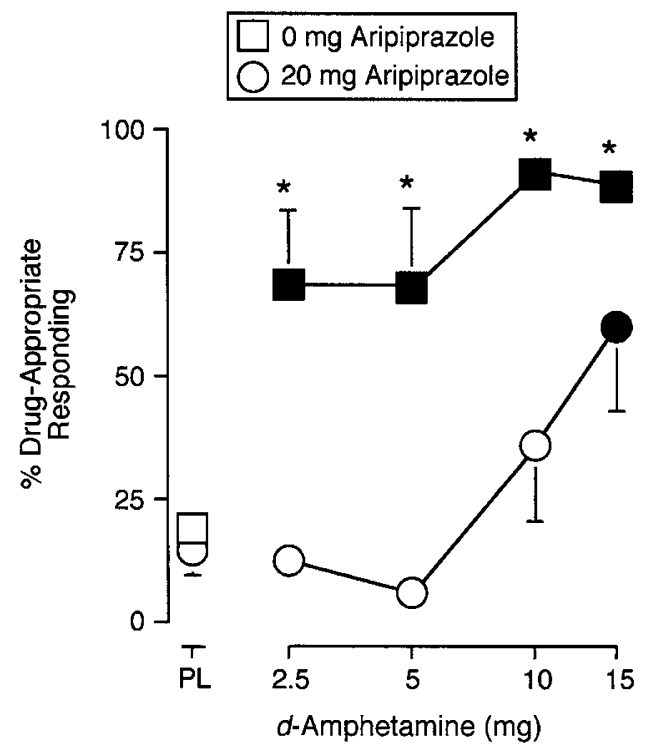

Figure I Percent drug-appropriate appropriate responding maintained by $\mathrm{D}$-amphetamine alone, aripiprazole alone, $\mathrm{D}$-amphetamine-aripiprazole combinations, and placebo. X-axis: D-amphetamine dose. Data points above PL represent values when the doses of aripiprazole were administered in combination with $0 \mathrm{mg} \mathrm{D}$-amphetamine. Data points above $2.5,5,10$, and 15 represent the effects of the D-amphetamine dose administered in combination with $0 \mathrm{mg}$ (squares) or $20 \mathrm{mg}$ (circles) aripiprazole. Data points show means of seven participants. Unidirectional brackets indicate I SEM. Filled symbols indicate those values that are significantly different from the placebo-placebo condition (ie square above $\mathrm{PL}$ ). An asterisk indicates a significant difference between the 0 and $20 \mathrm{mg}$ aripiprazole conditions at the indicated D-amphetamine dose

Scale of the Adjective-Rating Scale. D-Amphetamine $(5,10$, and $15 \mathrm{mg}$ ) alone increased these ratings significantly above placebo levels, whereas only the $15 \mathrm{mg}$ dose did so when Damphetamine was administered in combination with $20 \mathrm{mg}$ aripiprazole. Scores on this scale were significantly lower after administration of 5, 10, and $15 \mathrm{mg}$ D-amphetamine in combination with $20 \mathrm{mg}$ aripiprazole, relative to those doses alone. There were no statistically significant effects on the Sedative Scale of the Adjective-Rating Scale.

\section{Stimulant-Sensitive Adjective-Rating Scale}

ANOVA revealed a significant main effect of D-amphetamine on the Stimulant-Sensitive Adjective-Rating Scale (Table 1). D-Amphetamine (2.5, 5, 10, and $15 \mathrm{mg})$ alone increased the composite score significantly above placebo levels, whereas only the $15 \mathrm{mg}$ dose did so when Damphetamine was administered in combination with $20 \mathrm{mg}$ aripiprazole. Scores were significantly lower after administration of all active D-amphetamine doses in combination with $20 \mathrm{mg}$ aripiprazole, relative to those Damphetamine doses alone.

\section{Drug-Effect Questionnaire}

ANOVA revealed a significant interaction of aripiprazole and D-amphetamine on three items of the Drug-Effect Questionnaire: Good Effect, Like Drug, and Willing to Take 



Figure 2 Effects of D-amphetamine alone, aripiprazole alone, D-amphetamine-aripiprazole combinations, and placebo on the A, MBG, and PCAG scales of the ARCl, and ratings of Good Effect, Like Drug, and Willing to Take Again from the Drug-Effect Questionnaire. Data are expressed as AUC. All other details are as in Figure 1 .

Again (Table 1). Figure 2 shows the effects of $D$ amphetamine alone, and in combination with aripiprazole, for ratings on these items. This figure shows that every dose of D-amphetamine alone significantly increased ratings of Good Effect, whereas only the 10 and $15 \mathrm{mg}$ doses did so when D-amphetamine was administered in combination with $20 \mathrm{mg}$ aripiprazole. In addition, the combination of each dose of D-amphetamine with $20 \mathrm{mg}$ of aripiprazole decreased ratings of Good Effect relative to those doses of D-amphetamine alone. This figure also shows that the 5, 10, and $15 \mathrm{mg}$ doses of D-amphetamine alone significantly increased ratings of Like Drug and Willing to Take Again above placebo levels, whereas only the 10 and $15 \mathrm{mg}$ doses did so when D-amphetamine was administered in combination with $20 \mathrm{mg}$ aripiprazole. In addition, the combination of 5,10 , and $15 \mathrm{mg}$ of D-amphetamine with $20 \mathrm{mg}$ of aripiprazole decreased ratings of Like Drug and Willing to Take Again relative to those doses of $\mathrm{D}$-amphetamine alone. ANOVA revealed significant main effects of both D-amphetamine and aripiprazole on three items of the Drug-Effect Questionnaire: Active, Alert, Energetic; Heart Racing; and Shaky, Jittery (Table 1). Finally, ANOVA revealed a significant main effect of only D-amphetamine on six items of the Drug-Effect Questionnaire: Any Effect; Like Drug; Performance Improved; Willing to Pay For; Stimulated; and Talkative, Friendly (Table 1). For the items not shown in Figure 2, planned comparisons indicated that at least two doses of D-amphetamine alone significantly increased ratings above placebo levels. In addition, only the highest dose of D-amphetamine (eg $15 \mathrm{mg}$ ) in combination with $20 \mathrm{mg}$ of aripiprazole generally increased ratings on these measures, and, for all items but Any Effect, the combination of at least one dose of D-amphetamine and aripiprazole significantly decreased ratings relative to that dose alone.

\section{DSST}

ANOVA revealed significant main effects of $D$-amphetamine and aripiprazole (Table 1) on the number of trials correct and number of trials attempted on the DSST. A maximum increase of approximately $6 \%$ in the number of correct trials completed was observed at the $15 \mathrm{mg}$ D-amphetamine dose, although planned comparisons indicated that this was not significant (Figure 3). Similarly, a maximum increase of approximately $5 \%$ in the number of trials attempted was observed at the $15 \mathrm{mg}$ D-amphetamine dose, although planned comparisons indicated that this was also not significant (Figure 3). Administration of $20 \mathrm{mg}$ aripiprazole alone and in combination with $2.5 \mathrm{mg}$ of $\mathrm{D}$-amphetamine significantly decreased the number of trials correct and number of trials attempted relative to placebo. The largest decrement in performance was observed following administration of the $20 \mathrm{mg}$ aripiprazole alone, which resulted in a 

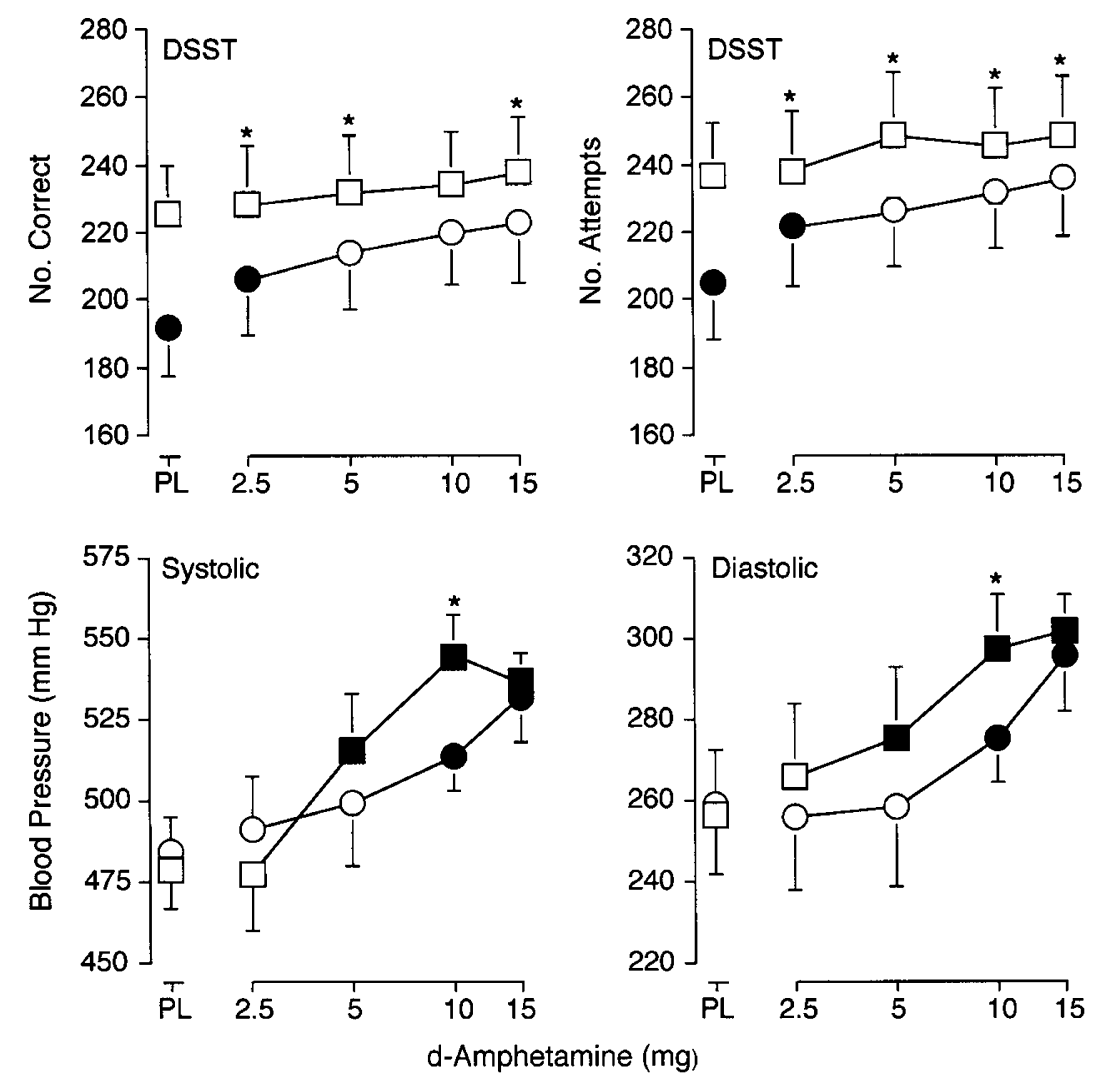

Figure 3 Effects of D-amphetamine alone, aripiprazole alone, D-amphetamine-aripiprazole combinations, and placebo on the number of trials correct and number of trials completed on the DSST, as well as systolic and diastolic blood pressure. Data are expressed as AUC. All other details are as in Figure I.

decrease of approximately 15 and 13\% in the number of correct trials completed and attempted, respectively. Administration of $20 \mathrm{mg}$ of aripiprazole in combination with $0,2.5,5,10$, and $15 \mathrm{mg}$ D-amphetamine significantly decreased the number of trials correct and the number of trials attempted on the DSST, relative to those doses of D-amphetamine alone.

\section{Heart Rate and Blood Pressure}

ANOVA revealed a significant interaction of aripiprazole and D-amphetamine on systolic and diastolic (Table 1) blood pressure. The 5, 10, and $15 \mathrm{mg}$ doses of $\mathrm{D}$ amphetamine alone significantly increased these measures above placebo levels, whereas only the 10 and $15 \mathrm{mg}$ doses did so when D-amphetamine was administered in combination with $20 \mathrm{mg}$ aripiprazole (Figure 3 ). The combination of $10 \mathrm{mg}$ D-amphetamine with $20 \mathrm{mg}$ of aripiprazole significantly decreased these measures relative to $10 \mathrm{mg}$ of $\mathrm{D}$ amphetamine alone. ANOVA did not reveal any significant effects on heart rate.

\section{DISCUSSION}

Aripiprazole was chosen for evaluation because it is a partial agonist at $\mathrm{D}_{2}$ receptors, and $\mathrm{D}_{2}$ partial agonists have shown promise in animal models of stimulant use. In addition, aripiprazole is associated with fewer untoward side effects (McGavin and Goa, 2002), which may limit the therapeutic potential of other atypical antipsychotics in stimulant-dependent individuals (eg Grabowski et al, 2000, 2004). Consistent with prior research, D-amphetamine alone functioned as a discriminative stimulus, produced positive subject-rated effects, and elevated cardiovascular indices (Chait et al, 1985; Heishman and Henningfield, 1991; Kollins and Rush, 1999; Rush et al, 1998, 2003, 2004). The behavioral effects of D-amphetamine peaked at approximately 2-3 h (data not shown), in agreement with previous human laboratory research (eg Chait et al, 1985; Rush et al, 1998) and the timecourse for peak plasma levels following oral administration (Angrist et al, 1987). Aripiprazole alone did not occasion D-amphetamine-appropriate responding or produce subject-rated effects, but modestly impaired performance. Both aripiprazole and D-amphetamine, alone and in combination, were well tolerated by all participants and no adverse events occurred. Concurrent administration of aripiprazole significantly attenuated the discriminativestimulus and cardiovascular effects of D-amphetamine, as well as some of the positive subject-rated drug effects.

In contrast to our previous studies using nearly identical procedures (eg Kollins and Rush, 1999; Rush et al, 1998, 2003, 2004), the dose-effect curve for the discriminativestimulus effects of D-amphetamine was not graded in that all 
doses of D-amphetamine engendered drug-appropriate responding significantly greater than placebo. The reasons for this finding are unknown, but may be related to the larger number of female participants enrolled (ie five women and two men), which is the reverse of our four previous studies. There is accumulating evidence that females may be more sensitive to the behavioral effects of stimulants (reviewed in Lynch et al, 2002). For example, a retrospective analysis of data combined from several studies from our laboratory in which women and men learned to discriminate $15 \mathrm{mg}$ D-amphetamine from placebo suggested that women were more sensitive to the discriminativestimulus effects of D-amphetamine (unpublished data). Consistent with that notion, four out of the five female participants in the present experiment reported greater than $60 \%$ drug-appropriate responding at the lowest (ie $2.5 \mathrm{mg}$ ) dose of D-amphetamine.

Aripiprazole alone did not occasion D-amphetamineappropriate responding, suggesting that aripiprazole did not exhibit agonist-like activity to the extent that $D_{2}$ receptors are involved in the discriminative stimulus produced by D-amphetamine. Administration of full agonists at this receptor subtype in animals trained to discriminate $\mathrm{D}$-amphetamine has resulted in full substitution in some studies (Callahan et al, 1991; Nielsen et al, 1989), whereas other investigators have reported inconsistent or only partial substitution (Jarbe, 1982; Kamien and Woolverton, 1989). Consistent with their intrinsic receptor efficacy, administration of the partial $\mathrm{D}_{2}$ agonists preclamol and SDZ 208-911 resulted in approximately $20-40 \%$ Damphetamine-appropriate responding in rats (Exner and Clark, 1992). These data suggest that the interoceptive stimulus produced by stimulation of $\mathrm{D}_{2}$ receptors constitute a portion, but not the whole, of the discriminative stimulus produced by D-amphetamine. Moreover, because the participants in the present study were only recreational stimulant users and their basal DA tone was presumably normal, aripiprazole may have functioned as an antagonist, even when administered alone. Therefore, it may not be unexpected that aripiprazole alone did not substitute for Damphetamine in the present study. Future research should enroll stimulant-dependent individuals who may have dysregulated DA systems.

In agreement with the drug-discrimination data, which suggest that aripiprazole did not produce a discernable interoceptive cue, there were no increases in subject ratings observed following administration of aripiprazole alone, despite the fact that antipsychotic drugs can produce sedative-like effects. These data are also concordant with a previous study from our laboratory in which the behavioral effects of D-amphetamine were determined in combination with the atypical antipsychotic risperidone (Rush et al, 2003). In that study, in which nearly identical procedures were employed, $1.0 \mathrm{mg}$ of risperidone did not occasion D-amphetamine-appropriate responding, nor did it increase subject ratings associated with sedation (ie PCAG scale of the ARCI; sedative subscale of the Adjective-Rating Scale; Sluggish, Fatigued, Lazy item from the Drug Effect Questionnaire).

Aripiprazole alone did, however, impair psychomotor performance as measured by a computerized version of the DSST, consistent with the well-documented effects of antipsychotic drugs on motor control. These results are concordant with our previous study using risperidone (Rush et al, 2003), which also found performance impairment on the DSST. Interestingly, aripiprazole did not increase subject ratings of Performance Impaired on the Drug Effect Questionnaire in the present study, indicating that, although aripiprazole produced decrements in psychomotor performance, participants were unable to perceive this change. Worth noting is that it appears that tolerance can develop to the adverse effects of antipsychotic drugs over the course of chronic treatment (Baldessarini and Tarazi, 2001).

The ability of a drug to block the discriminative-stimulus effects of a stimulant such as amphetamine may be important in preventing relapse. Some theorists have suggested that the discriminative-stimulus effects of a drug may signal further drug availability, which could result in an escalation of drug-seeking and/or drug-taking behavior (de Wit and Stewart, 1981). Furthermore, if the interoceptive cues of an abused drug continue to be blocked with repeated drug sampling, drug-related behaviors may extinguish over time. In the present experiment, concurrent administration of aripiprazole significantly attenuated the discriminative-stimulus effects of $\mathrm{D}$-amphetamine. These results are concordant with other studies that have examined the ability of various atypical antipsychotics to modify the discriminative-stimulus effects of D-amphetamine in animals (Nielsen and Jepsen, 1985) and humans (Rush et al, 2003). Similarly, these data are consistent with the ability of a partial $\mathrm{D}_{2}$ agonist to function as an antagonist in the presence of a drug that elevates synaptic DA. For example, in previous drug-discrimination experiments the partial $\mathrm{D}_{2}$ agonists terguride, SDZ 208-911 and SDZ 208-912 attenuated the discriminative-stimulus effects of D-amphetamine (Exner and Clark, 1992).

Concurrent administration of aripiprazole also significantly attenuated nearly all of the self-reported effects for which there was an effect of D-amphetamine. We have reported similar findings from our previous study in which the atypical antipsychotic risperidone was administered in combination with D-amphetamine (Rush et al, 2003). However, in the latter study, there was a reduction in the subject-rated effects of $\mathrm{D}$-amphetamine by risperidone on fewer of the measures. In particular, the subscales of the ARCI were less sensitive to risperidone administration compared to the other self-report questionnaires in that no significant differences between the D-amphetamine alone and D-amphetamine-risperidone combination conditions were found. In the present study, D-amphetamine increased scores on the A, BG, and MBG subscales, and planned comparisons revealed that aripiprazole significantly decreased these scores on each subscale. Although direct statistical comparisons across these two studies are not possible, it appears that, in general, the influence of aripiprazole on the subject-rated, as well as the discriminative-stimulus, effects of $\mathrm{D}$-amphetamine was more robust compared to risperidone. The underlying reasons for the possible differences between aripiprazole and risperidone are unknown, but may be dose related, or due to differences in their binding profile.

While the role of DA has been emphasized in the behavioral effects of stimulants, the involvement of 5-HT 
in the effects of aripiprazole observed in the present study is a possibility. Aripiprazole has significant affinity $(<30 \mathrm{nM})$ for, and has varying degrees of intrinsic efficacy at, the $5-\mathrm{HT}_{1 \mathrm{~A}}, 5-\mathrm{HT}_{2 \mathrm{~A}}, 5-\mathrm{HT}_{2 \mathrm{~B}}$, and $5-\mathrm{HT}_{7}$ receptor subtypes (Shapiro et al, 2003). The data regarding the influence of each of these 5-HT receptor subtypes in the behavioral effects of stimulants are limited and, in some cases, conflicting; therefore, it is difficult to draw conclusions about the role of 5-HT in the interactions of aripiprazole and D-amphetamine. While a comprehensive review of the available data is beyond the scope of this report, a few examples are provided. In one study, the partial $5-\mathrm{HT}_{1 \mathrm{~A}}$ agonists buspirone and gepirone attenuated the discriminative-stimulus effects of D-amphetamine in rhesus monkeys (Nader and Woolverton, 1994). In another study in rats, however, buspirone, but not gepirone, shifted the dose-effect curve for percent cocaine-appropriate responding rightward, which was attributed to the $\mathrm{DA} \mathrm{D}_{2}$ antagonist properties of the former drug (Callahan and Cunningham, 1997). Similarly, acute administration of buspirone, but not gepirone, appeared to antagonize the reinforcing effects of cocaine in rhesus monkeys (Gold and Balster, 1992). In a study with risperidone, a mixed $\mathrm{D}_{2}$ and $5-\mathrm{HT}_{2}$ receptor antagonist, raclopride, a $\mathrm{D}_{2}$ antagonist, and ritanserin, a $5-\mathrm{HT}_{2}$ antagonist in rats, self-administration of $\mathrm{D}$-amphetamine was attenuated by risperidone and raclopride, but not ritanserin (Fletcher, 1998). In another study in rats, however, ritanserin inhibited a D-amphetamine conditioned place preference (Nomikos and Spyraki, 1988). Worth noting is that aripiprazole also has significant affinity for other receptor subtypes, including $\mathrm{D}_{3}$, adrenergic $\alpha_{1 \mathrm{~A}}$, and histamine $\mathrm{H}_{1}$ (Shapiro et al, 2003). The degree of involvement of these other receptors in the present study is also unknown.

One caveat of this study is the small number of participants that were enrolled. The number of subjects enrolled was based on power calculations from previous studies using nearly identical methods (Rush et al, 2003, 2004). In addition, a sample size of seven participants is consistent with prior drug-discrimination studies in humans in which drug pretreatments or combinations were administered in an attempt to modify the discriminativestimulus effects of a stimulant (eg Hart et al, 2002; Lile et al, 2004; Oliveto et al, 1997; Perkins et al, 1999; Rush et al, $2003,2004)$. In our previous studies with alprazolam and risperidone, a significant attenuation of the discriminativestimulus and some of the positive subject-rated effects of the higher doses of D-amphetamine was observed with six and eight subjects, respectively (Rush et al, 2003, 2004). Similarly, in six participants that had learned to discriminate caffeine, triazolam shifted the dose-effect curve for percent drug-appropriate responding rightward (Oliveto et al, 1997). In another study, the cholinergic antagonist mecamylamine attenuated the discriminative-stimulus effects and some of the subject-rated effects of nicotine in the same number of participants (Perkins et al, 1999). The positive results from those studies, as well as the present results, suggest that this sample size is suitable for detecting an antagonism of the behavioral effects of a stimulant.

The rationale for using an antagonist to treat drug dependence is that by blocking the acute, abuse-related effects of the drug, drug-seeking and drug-taking behaviors will extinguish over time. However, if the user is maintained on a competitive antagonist, they may increase the amount of self-administered drug to overcome the effects of the antagonist. This is an inherent limitation to the use of a competitive antagonist to treat drug dependence and is another caveat of the present study. Relatively low doses of D-amphetamine were tested in this experiment, and the ability of aripiprazole to attenuate the discriminativestimulus and subject-rated effects of D-amphetamine appeared to be surmountable, which limits the conclusions that can be drawn regarding the therapeutic potential of aripiprazole. That the effects of aripiprazole were surmountable is consistent with an interaction between a partial agonist (ie aripiprazole) acting as a competitive antagonist in the presence of an agonist (ie DA released by Damphetamine) at $D_{2}$ receptors. Nevertheless, the present study has established that aripiprazole can be safely administered in combination with a stimulant. Future studies should test multiple doses of aripiprazole, and higher amphetamine doses. Worth noting is that $20 \mathrm{mg}$ of aripiprazole is in the mid range of the doses indicated for the treatment of schizophrenia (10-30 mg; McGavin and Goa, 2002); therefore, additional doses of aripiprazole could be tested to determine the degree to which its effects are surmountable.

A final caveat of this study is that the combination of a stimulant with a drug having sedative-like effects in a laboratory setting may lead to false positives with respect to the ability of the putative treatment to pharmacologically antagonize the effects of the stimulant. In a recently completed study from our laboratory using nearly identical methods, the benzodiazepine oxazepam did not modify the discriminative-stimulus or subject-rated effects of D-amphetamine, but did increase ratings of sedation and impaired psychomotor performance (Lile et al, under review). Those results, as well as the finding that the effects of aripiprazole were surmountable, indicate that the findings from the present study may represent a true pharmacological antagonism of the behavioral effects of D-amphetamine by aripiprazole, and suggest that aripiprazole, or similar drugs, deserve further study as potential pharmacotherapies for the management of stimulant dependence. Future laboratory studies should investigate the ability of aripiprazole to attenuate the behavioral effects of stimulants associated with a greater degree of dependence, such as methamphetamine or cocaine, in dependent individuals. However, only through the conduct of placebocontrolled clinical trials can the efficacy of aripiprazole in the management of stimulant dependence be determined. Moreover, only through the conduct of future placebocontrolled clinical trials can the public-health relevance and predictive validity of laboratory-based research be ascertained.

\section{ACKNOWLEDGEMENTS}

We thank Frances Wagner, RN, for her expert medical assistance and John Blackburn, Michelle Gray, Jamie Haga, Angela Owens, Derek Roe and Thomas Wooters for their skilled technical assistance. 


\section{REFERENCES}

Angrist B, Corwin J, Bartlik B, Cooper T (1987). Early pharmacokinetics and clinical effects of oral D-amphetamine in normal subjects. Biol Psychiatry 22: 1357-1368.

Baldessarini RJ, Tarazi FI (2001). Drugs and the treatment of psychiatric disorders. In: Hardman JG, Limbird LE, Gilman AG (eds). Goodman and Gilman's The Pharmacological Basis of Therapeutics. McGraw-Hill: New York. p 500.

Burris KD, Molski TF, Xu C, Ryan E, Tottori K, Kikuchi T et al (2002). Aripiprazole, a novel antipsychotic, is a high-affinity partial agonist at human dopamine $\mathrm{D}_{2}$ receptors. J Pharmacol Exp Ther 302: 381-389.

Callahan PM, Appel JB, Cunningham KA (1991). Dopamine $D_{1}$ and $\mathrm{D}_{2}$ mediation of the discriminative stimulus properties of D-amphetamine and cocaine. Psychopharmacology 103: 50-55.

Callahan PM, Cunningham KA (1997). Modulation of the discriminative stimulus properties of cocaine: comparison of the effects of fluoxetine with $5-\mathrm{HT}_{1 \mathrm{~A}}$ and $5-\mathrm{HT}_{1 \mathrm{~B}}$ receptor agonists. Neuropharmacology 36: 373-381.

Chait LD, Uhlenhuth EH, Johanson CE (1985). The discriminative stimulus and subjective effects of $d$-amphetamine in humans. Psychopharmacology 86: 307-312.

Childress AR, O'Brien CP (2000). Dopamine receptor partial agonists could address the duality of cocaine craving. Trends Pharmacol Sci 21: 6-9.

de Wit H, Stewart J (1981). Reinstatement of cocaine-reinforced responding in the rat. Psychopharmacology 75: 134-143.

Di Marino ME, Haberny KA, Felch LJ, Walsh SL, Preston KL, Bigelow GE (1998). Development of a subjective rating scale sensitive to acute cocaine administration. National Institute on Drug Abuse Research Monograph Series, Problems of Drug Dependence, 1997: Proceedings of the 59th Annual Scientific Meeting, vol. 178, Scottsdale, AZ, p 139.

Exner M, Clark D (1992). Agonist and antagonist activity of low efficacy $\mathrm{D}_{2}$ dopamine receptor agonists in rats discriminating $d$-amphetamine from saline. Behav Pharmacol 3: 609-619.

Fletcher PJ (1998). A comparison of the effects of risperidone, racloride, and ritanserin on intravenous self-administration of $d$-amphetamine. Pharmacol Biochem Behav 60: 55-60.

Gold LH, Balster RL (1992). Effects of buspirone and gepirone on i.v. cocaine self-administration in rhesus monkeys. Psychopharmacology 108: 289-294.

Gonzalez G, Oliveto A, Kosten TR (2004). Combating opiate dependence: a comparison among the available pharmacological options. Expert Opin Pharmacother 5: 713-725.

Grabowski J, Rhoades H, Silverman P, Schmitz JM, Stotts A, Creson D et al (2000). Risperidone for the treatment of cocaine dependence: randomized, double-blind trial. J Clin Psychopharmacol 20: 305-310.

Grabowski J, Rhoades H, Stotts A, Cowan K, Kopecky C, Dougherty A et al (2004). Agonist-like or antagonist-like treatment for cocaine dependence with methadone for heroin dependence: two double-blind randomized clinical trials. Neuropsychopharmacology 29: 969-981.

Hart CL, Haney M, Foltin RW, Fischman MW (2002). Effects of the NMDA antagonist memantine on human methamphetamine discrimination. Psychopharmacology 164: 376-384.

Heishman SJ, Henningfield JE (1991). Discriminative stimulus effects of $d$-amphetamine, methylphenidate, and diazepam in humans. Psychopharmacology 103: 436-442.

Izzo E, Orsini C, Koob G, Pulvirenti L (2001). A dopamine partial agonist and antagonist block amphetamine self-administration in a progressive-ratio schedule. Pharmacol Biochem Behav 68: 701-708.

Jarbe TU (1982). Discriminative stimulus properties of damphetamine in pigeons. Pharmacol Biochem Behav 17: 671-675.
Jasinski D (1977). Assessment of the abuse potentiality of morphine-like drugs (methods used in man). In: Morton WR (ed). Drug Addiction I. Springer-Verlag: New York. pp 197-258.

Kamien JB, Woolverton WL (1989). A pharmacological analysis of the discriminative stimulus properties of $d$-amphetamine in rhesus monkeys. J Pharmacol Exp Ther 241: 213-217.

Kollins SH, Rush CR (1999). Effects of training dose on the relationship between discriminative-stimulus and self-reported drug effects of $d$-amphetamine in humans. Pharmacol Biochem Behav 64: 319-326.

Lile JA, Stoops WW, Glaser PE, Hays LR, Rush CR (2004). Acute administration of the GABA reuptake inhibitor tiagabine does not alter the effects of oral cocaine in humans. Drug Alcohol Depend 76: 81-91.

Lynch WJ, Roth ME, Carroll ME (2002). Biological basis of sex differences in drug abuse: preclinical and clinical studies. Psychopharmacology 164: 121-137.

Martin WR, Sloan JW, Sapira JD, Jasinski DR (1971). Physiologic, subjective, and behavioral effects of amphetamine, methamphetamine, ephedrine, phenmetrazine, and methylphenidate in man. Clin Pharmacol Ther 12: 245-258.

McGavin JK, Goa KL (2002). Aripiprazole. CNS Drugs 16: 779-786.

McLeod DR, Griffiths RR, Bigelow GE, Yingling JE (1982). An automated version of the digit symbol substitution test (DSST). Behav Res Methods Instr 14: 463-466.

Nader MA, Woolverton WL (1994). Blockade of the discriminative stimulus effects of $d$-amphetamine in rhesus monkeys with serotonin 5- $\mathrm{HT}_{1 \mathrm{~A}}$ agonists. Behav Pharmacol 5: 591-598.

Nielsen EB, Jepsen SA (1985). Antagonism of the amphetamine cue by both classical and atypical antipsychotic drugs. Eur J Pharmacol 111: 167-176.

Nielsen EB, Randrup K, Andersen PH (1989). Amphetamine discrimination: effects of dopamine receptor agonists. Eur $J$ Pharmacol 160: 253-262.

Nomikos GG, Spyraki C (1988). Effects of ritanserin on the rewarding properties of $\mathrm{d}$-amphetamine, morphine and diazepam revealed by conditioned place preference in rats. Pharmacol Biochem Behav 30: 853-858.

Oliveto AH, Bickel WK, Hughes JR, Shea PJ, Higgins ST, Fenwick JW (1992). Caffeine drug discrimination in humans: acquisition, specificity and correlation with self-reports. J Pharmacol Exp Ther 261: 885-894.

Oliveto AH, Bickel WK, Hughes JR, Higgins ST, Badger G (1997). Functional antagonism of the caffeine-discriminative stimulus by triazolam in humans. Behav Pharmacol 8: 124-138.

Orsini C, Koob GF, Pulvirenti L (2001). Dopamine partial agonist reverses amphetamine withdrawal in rats. Neuropsychopharmacology 25: 789-792.

Perkins KA, Sanders M, Fonte C, Wilson AS, White W, Stiller R et al (1999). Effects of central and peripheral nicotinic blockade on human nicotine discrimination. Psychopharmacology 142: 158-164.

Pulvirenti L, Balducci C, Piercy M, Koob GF (1998). Characterization of the effects of the partial dopamine agonist terguride on cocaine self-administration in the rat. J Pharmacol Exp Ther 286: 1232-1238.

Rush CR, Kollins SH, Pazzaglia PJ (1998). Discriminative-stimulus and participant-rated effects of methylphenidate, bupropion, and triazolam in $d$-amphetamine-trained humans. Exp Clin Psychopharmacol 6: 32-44.

Rush CR, Stoops WW, Hays LR, Glaser PEA (2004). Alprazolam attenuates the discriminative-stimulus effects of $d$-amphetamine in humans. J Clin Psychopharmacol 24: 410-420.

Rush CR, Stoops WW, Hays LR, Glaser PEA, Hays LS (2003). Risperidone attenuates the discriminative-stimulus effects of d-amphetamine in humans. J Pharmacol Exp Ther 306: 195-204. 
Shapiro DA, Renock S, Arrington E, Chiodo LA, Liu LX, Sibley DR et al (2003). Ariprazole, a novel atypical antipsychotic drug with a unique and robust pharmacology. Neuropsychopharmacology 28: $1400-1411$.

Substance Abuse and Mental Health Services Administration (SAMHSA) (2003). Results from the 2002 National Survey on Drug Use and Health: National findings. Office of Applied Studies Publications and Data Dissemination: Rockville, MD.

Substance Abuse and Mental Health Services Administration (SAMHSA) (2004). Drug and Alcohol Services Information System (DASIS) report. Primary Methamphetamine/Amphetamine Treatment Admissions Increase: 1992-2002. Office of Applied Studies Publications and Data Dissemination: Rockville, MD.

United Nations Office on Drugs and Crime (2003). Ecstasy and Amphetamines Global Survey 2003. United Nations: New York, NY.

Volkow ND, Wang GJ, Fowler JS, Logan J, Gatley SJ, Wong C et al (1999). Reinforcing effects of stimulants in humans are associated with increases in brain dopamine and occupancy of $\mathrm{D}_{2}$ receptors. J Pharmacol Exp Ther 291: 409-415.

Weiss F, Markou A, Lorang MT, Koob GF (1992). Basal extracellular dopamine levels in the nucleus accumbens are decreased during cocaine withdrawal after unlimited-access selfadministration. Brain Res 593: 314-318.

Yacoubian GS, Peters RJ (2004). Exploring the prevalence and correlates of methamphetamine use: findings from Sacramento's ADAM program. J Drug Educ 34: 281-294. 